\title{
Production of Phospholipase C (Alpha-toxin), Haemolysins and Lethal Toxins by Clostridium perfringens Types A to D
}

\author{
By R. MÖLLBY AND T. HOLME \\ Department of Bacteriology, Karolinska Institutet, $S$-IO4 OI \\ Stockholm 60, Sweden \\ AND C.-E. NORD, C. J. SMYTH* AND T. WADSTRÖM* \\ Department of Bacteriology, Statens Bakteriologiska Laboratorium, \\ S-105 21 Stockholm
}

(Received 3 February 1976; revised 20 April 1976)

SUMMAR Y

To obtain high yields of extracellular enzymes and toxins for immunological analysis, type culture collection strains of Clostridium perfringens types $\mathrm{A}$ to $\mathrm{D}$ and 28 fresh isolates of $C$. perfringens type A from humans were grown in fermenters under controlled conditions in a pre-reduced proteose peptone medium. The type culture collection strains all showed different characteristics with respect to growth rates and $\mathrm{pH}$ optima for growth. Production of phospholipase $\mathrm{C}$ (alpha-toxin), haemolysin and lethal activity varied considerably between the different types. Growth and extracellular protein production in fermenters with $\mathrm{pH}$ control and static or stirred cultures were compared. Production of all extracellular proteins measured was markedly improved by cultivation in fermenters with $\mathrm{pH}$ control.

Strain ATCCI3I24 produced five times more phospholipase $C$ than any of 28 freshly isolated strains of $C$. perfringens type A, grown under identical conditions. Haemolytic and lethal activities of the ATCC strain were equal or superior to the activities of any of the freshly isolated strains. There were no differences in the bacterial yields and in the production of extracellular toxins between type A strains isolated from clinical cases of gas gangrene and abdominal wounds, and those isolated from faecal samples from healthy persons.

\section{INTRODUCTION}

Strains of Clostridium perfringens are divided into five types, A to E, according to the major lethal extracellular proteins they produce, namely alpha-, beta-, epsilon- and iota-toxins (Wilsdon, 1931). The method generally used for typing strains of C. perfringens (Smith \& Holdeman, I968; Willis, 1969; Hauschild, I971 ; Smith, 1973) is a cumbersome one involving the neutralization of the toxins with specific antisera and injection of the toxin-antiserum mixtures into mice. A rapid in vitro technique for typing is desirable, and immunoelectrophoretic analysis of extracellular toxins and enzymes might form the basis of a suitable method. As part of the development of such a system, we investigated the formation of clostridial antigens under defined culture conditions. An earlier report (Nord et al., 1974) described the optimum conditions for growth of, and formation of alpha-toxin (phospholipase C) and theta-toxin by C. perfringens type A, strain ATCCI3124.

\footnotetext{
* Present address: Department of Bacteriology and Epizootologi, Veterinärhögskolan, Biomedicum, Box 583, S-75I 23, Uppsala, Sweden.
} 
We have investigated the production of extracellular enzymes and toxins from representative strains of $C$. perfringens types $\mathrm{A}$ to $\mathrm{D}$ in batch culture in fermenters to select optimal conditions for their formation. Type $\mathrm{E}$ was not investigated because of its rarity as a causative agent of disease. Since laboratory strains may lose their ability to produce certain extracellular products, the culture collection strains were compared with strains newly isolated from both healthy persons and patients with clostridial infections.

\section{METHODS}

Chemicals. All chemicals were of analytical grade unless otherwise stated. The salts and constituents for buffers were obtained from Merck, Darmstadt, Germany.

Bacterial strains. Clostridium perfringens type A (ATCCI3I24), type B (ATCC3626), type $\mathrm{C}(\mathrm{ATCC} 3628)$ and type D (ATCC3629) were obtained from the American Type Culture Collection, Rockville, Maryland, U.S.A. Clostridium perfringens type A (NCTCI 265), type B (NCTC 3I Io), type C (NCTC3I 80) and type D (NCTC8346) were obtained from the National Collection of Type Cultures, London. The anaerobic culture system, including the special equipment for subculturing (Bellco, New Jersey, U.S.A.) developed by the Anaerobe Laboratory, Virginia Polytechnic Institute and State University (see Holdeman \& Moore, 1973), was used for subculturing the strains. Fourteen clinical isolates from patients with gas gangrene (I0) and abdominal wounds (4) and I4 faecal isolates from healthy persons were used. These strains were identified as $C$. perfringens type $A$ at the National Bacteriological Laboratory, Stockholm, Sweden, according to the method described by Holdeman \& Moore (1973). They were directly subcultured only once, and then grown in fermenters.

Preparation of pre-reduced medium. The medium used contained: Difco proteose peptone, $20 \mathrm{~g}$; Difco yeast extract, $5 \mathrm{~g}$; sodium chloride, $5 \mathrm{~g}$; L-cysteine, $0.5 \mathrm{~g}$; and distilled water to a final volume of I 1. It was pre-reduced as described by Nord et al. (I974). Glucose $\left(5 \mathrm{~g}^{-1}\right)$ was sterilized by filtration and added aseptically to the basal medium.

Culture technique. Stirred fermenters with a working volume of 31 were used for all cultivations (FL 103, Biotec, Stockholm, Sweden). Batch cultures were inoculated by adding $300 \mathrm{ml}$ of a culture grown overnight in pre-reduced medium (final dry weight of bacteria in inoculum, I to $2 \mathrm{mg} \mathrm{m}^{-1}$ ). Temperature was controlled to $\pm 0.0 \mathrm{I}{ }^{\circ} \mathrm{C}$, and $\mathrm{pH}$ to $\pm 0.05 \mathrm{pH}$ unit. The impeller speed was $400 \mathrm{rev}$. $\mathrm{min}^{-1}$ and an anaerobic atmosphere was maintained by bubbling oxygen-free nitrogen through the culture at a rate of $0.051 \mathrm{~min}^{-1}$ (Nord et al., I974). Samples (Io ml) were centrifuged at $4000 \mathrm{~g}$ for $\mathrm{I} 5 \mathrm{~min}$, the pellets were washed once in $0.0 \mathrm{I} \mathrm{M}$-phosphate buffer $\mathrm{pH} 6.5$ containing formaldehyde $(2 \%, w / v)$, and dried at $110{ }^{\circ} \mathrm{C}$ for $\mathrm{I} 8 \mathrm{~h}$ before weighing. All weights were corrected for the weight of the buffer salts.

Determination of phospholipase $C$ activity. A titrimetric method with a suspension of egg yolk in $0.15 \mathrm{M}-\mathrm{NaCl}$ supplemented with $10 \mathrm{mM}-\mathrm{CaCl}_{2}$ and $0 . \mathrm{I} \mathrm{mM}-\mathrm{ZnCl}_{2}$ as substrate (Möllby \& Wadström, 1973) was used. One unit (u.) of phospholipase C (EC. 3. I.4.3) activity was defined as the amount of enzyme that liberated $\mathrm{I} \mu \mathrm{mol}$ of titratable $\mathrm{H}^{+}$in $\mathrm{I}$ min.

Determination of haemolysin activity. Serial twofold dilutions of culture supernatants were made in Linbro trays (Flow Laboratories, Irvine, Scotland) in Tris/HCl buffered saline ( $0.15 \mathrm{M}-\mathrm{NaCl}$ containing $0.02 \mathrm{M}$-Tris $/ \mathrm{HCl}, \mathrm{pH} .0$ ), and an equal volume of $\mathrm{I} \%(\mathrm{v} / \mathrm{v})$ washed sheep erythrocytes was added. Haemolysis was estimated visually after 60 min at $37^{\circ} \mathrm{C}$ and finally determined after $\mathrm{I} 20 \mathrm{~min}$ at $4{ }^{\circ} \mathrm{C}$, when the erythrocytes had settled (Nord et al., I974). No 'hot-cold' haemolysis was observed (Möllby \& Wadström, 1973). One haemolytic unit (h.u.) was defined as the amount of haemolysin which gave $50 \%$ haemolysis after the period of incubation. 
Other enzyme assays. Leucine aminopeptidase (EC. 3.4.II.I) was assayed as described by Goldbarg \& Rutenberg (I965), malate dehydrogenase (EC. I.I.I.37) according to Murphey et al. (I967) and protease as described by Arvidson, Holme \& Wadström (I97I).

Determination of toxicity. Each twofold dilution of a sample was injected intraperitoneally $(0.5 \mathrm{ml})$ into two adult Swiss white mice $(40 \mathrm{~g})$. The highest dilution of sample causing death of both mice within $24 \mathrm{~h}$ was designated as one lethal dose. Filtering the sample through a Millipore Millex $0.22 \mu \mathrm{m}$ disposable filter unit prior to injection did not influence the results. Epsilon-protoxin was activated by incubating the supernatant with trypsin (O.I mg ml-1; trypsin I:250; Difco batch no. 588020) at $\mathrm{pH} 6.2$ for $30 \mathrm{~min}$ at $37^{\circ} \mathrm{C}$ immediately before testing in vivo. The increase in number of lethal doses per $\mathrm{ml}$ after trypsin activation was taken to represent epsilon-toxin (Smith, I973). Intraperitoneal injection of the toxin has been reported to be the most sensitive method of testing the lethal activity of clostridial toxins (Lynch \& Moskowitz, 1968).

Determination of number of antigens. This was done by counting precipitate lines obtained by crossed immunoelectrophoresis using a microtechnique and culture supernatant fluid concentrated 40 to 50 times (Weeke, I973). Antiserum against $C$. perfringens ATCCI3I 24 type A was raised in a rabbit by five successive intramuscular injections, at 3-week intervals, of I ml culture supernatant mixed with an equal amount of Freund's complete adjuvant. After a sixth immunization without adjuvant, the rabbit was bled and the serum used for serological analysis.

Commercial antisera. Antisera for neutralization tests were purchased from the Pasteur Institute, Paris: type A, I500 u. $\mathrm{ml}^{-1}$; type $\mathrm{B}, \mathrm{I} 100 \mathrm{u} . \mathrm{ml}^{-1}$; type $\mathrm{C}, 3000 \mathrm{u} . \mathrm{ml}^{-1}$; type $\mathrm{D}$, 600 u. $\mathrm{ml}^{-1}$.

\section{RESULTS}

\section{Culture of ATCC strains}

The four ATCC strains of $C$. perfringens types A to D were cultivated in fermenters at different $\mathrm{pH}$ in order to determine the optimum $\mathrm{pH}$ for production of extracellular toxins. The types differed both in their optimum $\mathrm{pH}$ for growth and in their capacity to produce the extracellular toxins assayed (Table I). Figure I shows typical growth curves for each type at their respective $\mathrm{pH}$ optima. Bacterial yields were limited by the glucose supply. Earlier studies had indicated that an increase in the glucose concentration of the medium resulted only in a small increase in the final bacterial weight but no increase in the yields of phospholipase C or haemolysin (Nord et al., 1974). The growth rates of the type strains were very different but maximum activities of both extracellular toxins were always found when growth ceased. For each strain, growth at the optimum $\mathrm{pH}$ resulted in the maximum yields of extracellular toxins; but there was a marked difference in the yield of phospholipase C, haemolysin and lethal toxins between the different strains. No leucine aminopeptidase or malate dehydrogenase was detected in the extracellular culture fluids indicating that very little cell lysis had occurred.

As previous workers (Smith \& Holdeman, I968; Willis, I969; Hauschild, I971; Smith, 1973) had used different culture conditions, we attempted to reproduce their conditions and compare the amounts of bacterial growth and production of phospholipase and haemolysin in such cultures with those in cultures grown in fermenters. Cultures were grown in the same pre-reduced medium in flasks with and without stirring and without $\mathrm{pH}$ control. In static cultures bacteria grew more slowly and usually to a lower final dry weight than in fermenter cultures (Table 2). Production of phospholipase and haemolysin was also very low compared with that in fermenters. Stirred cultures grew faster than static ones, but the final cell 


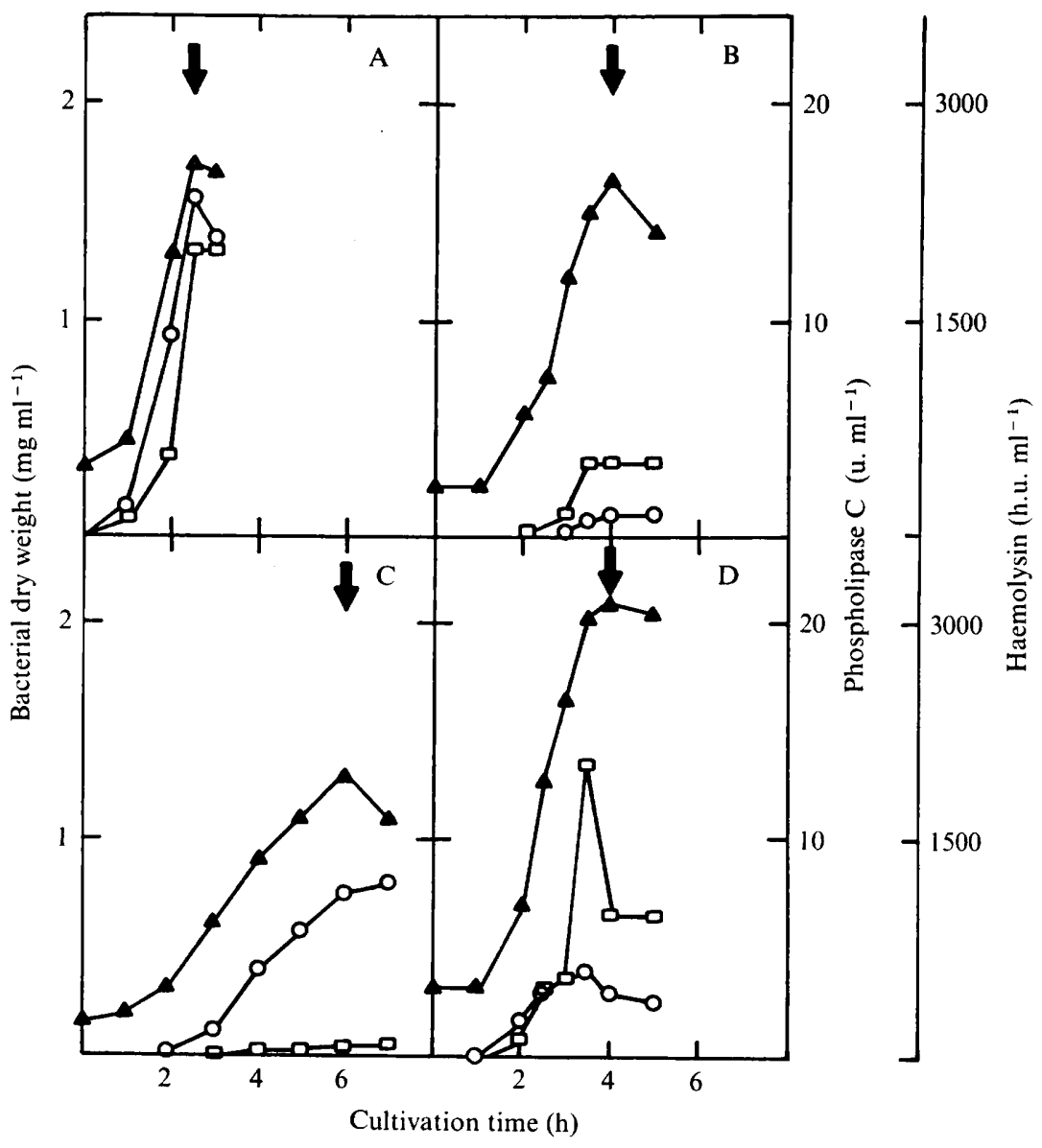

Fig. I. Growth and phospholipase $\mathrm{C}$ and haemolytic activities in fermenter cultures of ATCC strains of $C$. perfringens types $A$ to $\mathrm{D}$ in a proteose peptone medium supplemented with $0.5 \%$ (w/v) glucose, at optimum pH (see Table I): $\Delta$, bacterial dry weight; $O$, phospholipase $C$ activity; $\square$, haemolytic activity. Arrows indicate the time of exhaustion of medium glucose as indicated by cessation of acid production.

Table I. Growth and production of extracellular toxins of C. perfringens types $A$ to $D$ (ATCC strains) at optimum $p H$

Strain type and no.

\begin{tabular}{cccc}
\hline A & B & C & D \\
ATCC13124 & ATCC3626 & ATCC3628 & ATCC3629 \\
4 & 3 & 3 & 4 \\
$6 \cdot 8$ & $6 \cdot 4$ & $6 \cdot 0$ & $6 \cdot 4$ \\
$2 \cdot 5$ & $4 \cdot 0$ & $6 \cdot 0$ & $3 \cdot 5$ \\
$1 \cdot 6-1 \cdot 9$ & $\mathrm{I} \cdot 5-1 \cdot 7 \ddagger$ & $1 \cdot 3-1 \cdot 4$ & $\mathrm{I} \cdot 7-2 \cdot \mathrm{I}$ \\
$1 \mathrm{I}-15$ & $0 \cdot 5-1 \cdot 0$ & $7-8$ & $2 \cdot 5-4 \cdot 0$ \\
$2048-4096$ & $256-512$ & $32-64$ & $512-4096$ \\
32 & 160 & $16-32$ & 8
\end{tabular}

Number of cultures at indicated $\mathrm{pH}$ $\mathrm{pH}^{*}$

Time to maximum yield $\dagger(\mathrm{h})$

Dry weight $\left(\mathrm{mg} \mathrm{ml}^{-1}\right)$

Phospholipase C (u. $\left.\mathrm{ml}^{-1}\right)$

Haemolysin (h.u. $\mathrm{ml}^{-1}$ )

Toxicity $\left(\mathrm{LD}_{50} \mathrm{ml}^{-1}\right)$

32

$16-32$

8

* Each type was cultivated at $\mathrm{pH} 6 \cdot 0,6.4$ and 6.8; type $\mathrm{C}$ was also cultivated at $\mathrm{pH} 5.5$. The optimum $\mathrm{pH}$ is shown.

$\dagger$ After the indicated times, dry weight and toxicity decreased (see Fig. I).

$\ddagger$ Assayed on samples from only two cultures. 
Takle 2. Comparison of growth and production of extracellular phospholipase and haemolysin by $C$. perfringens types $A$ to $D$ (ATCC strains) under different culture conditions

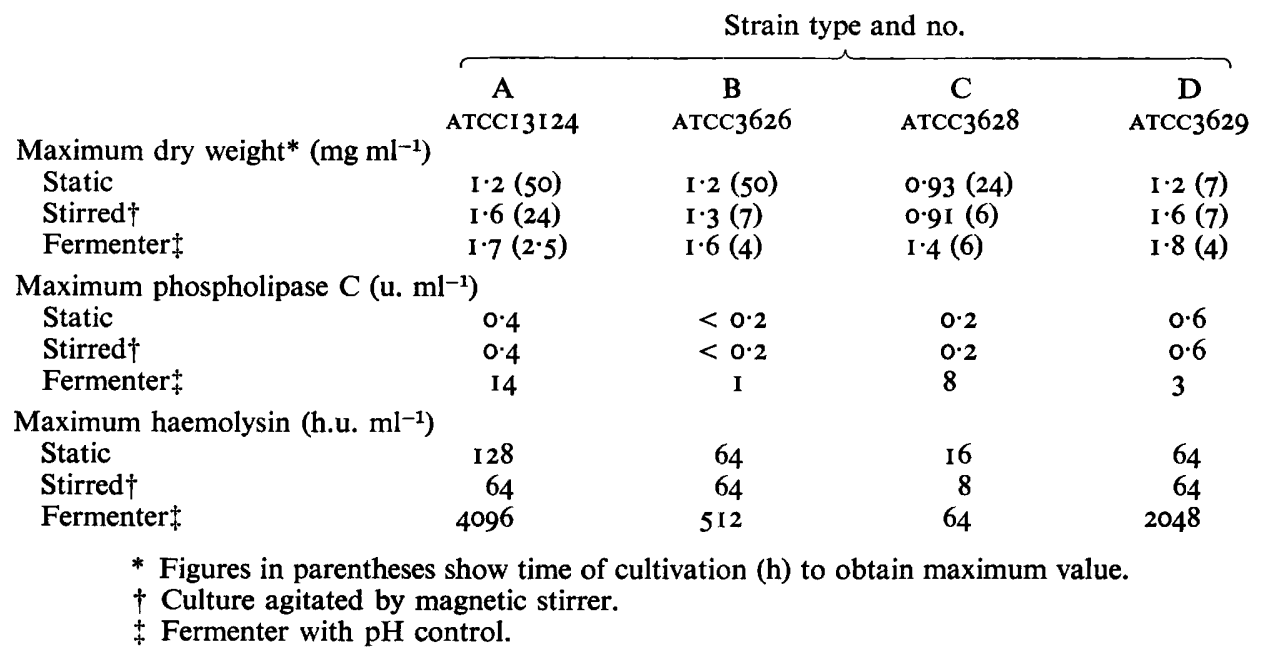

Table 3. Formation of extracellular toxins of C. perfringens types $A$ to $D$ (NCTC strains) grown at $\mathrm{pH} 6.4$

\begin{tabular}{|c|c|c|c|c|}
\hline & \multicolumn{4}{|c|}{ Strain type and no. } \\
\hline & $\underset{\text { NCTCI } 265}{A}$ & $\begin{array}{c}\text { B } \\
\text { NCTC3I Io }\end{array}$ & $\begin{array}{c}\mathrm{C} \\
\text { NCTC } 3180^{2}\end{array}$ & $\begin{array}{c}\text { D } \\
\text { NCTC8346 }\end{array}$ \\
\hline Time to maximum yield* (h) & $5 \cdot 5$ & 2.5 & 2.5 & 2.5 \\
\hline Dry weight $\left(\mathrm{mg} \mathrm{ml}^{-1}\right)$ & $\mathbf{I} \cdot \mathbf{3}$ & $I \cdot 4$ & $I \cdot 2$ & $I \cdot 4$ \\
\hline Phospholipase C (u. $\mathrm{ml}^{-1}$ ) & $<0.2$ & $<0.2$ & $\mathbf{I} \cdot \mathbf{2}$ & $0 \cdot 2$ \\
\hline Haemolysin (h.u. ml-1) & 512 & 512 & 256 & 4 \\
\hline Toxicity $\left(\mathrm{LD}_{50} \mathrm{ml}^{-1}\right)$ & $<2$ & I6 & 32 & $<2$ \\
\hline
\end{tabular}

* After the indicated times, dry weight and toxicity decreased.

concentration and the yield of toxins were not significantly different. The reason for the marked differences in the yields of phospholipase $\mathrm{C}$ and haemolysin between non-fermenter and fermenter cultures may be ascribed to the development of a low $\mathrm{pH}$ in the former. The final $\mathrm{pH}$ value of these cultures was usually about 5 . At this $\mathrm{pH}$, production of the toxins is greatly impaired (Nord et al., 1974).

\section{Culture of NCTC strains}

For comparison, NCTC strains types A to D were cultured in fermenters. These strains had different $\mathrm{pH}$ optima for growth compared with the ATCC strains tested, and also differed in their growth rates, maximum growth yields and production of extracellular toxins. Table 3 shows the results obtained with these strains cultivated at pH 6.4.

\section{Culture of C. perfringens strains of clinical and faecal origin}

For comparison of the growth characteristics and the production of extracellular products, I4 newly isolated strains of $C$. perfringens type A, Io from clinical cases of gas gangrene and four from abdominal wounds, and I4 strains from normal faecal samples were 


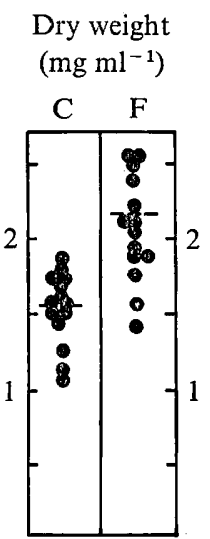

$(1 \cdot 9)$

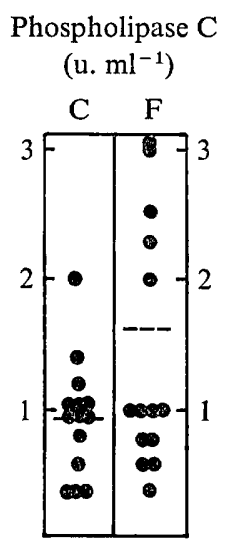

(15)
Haemolysin

(h.u. $\mathrm{ml}^{-1}$ )
Toxicity

$\left(\mathrm{LD}_{50} \mathrm{ml}^{-1}\right)$
No. of

antigens

Fig. 2. Growth and formation of extracellular toxins and antigens in fermenter culture by 28 newly isolated strains of $C$. perfringens type A. C, strains isolated from clinical cases of gas gangrene and abdominal wounds; F, strains isolated from faeces of healthy persons. Each represents one strain and dashed lines indicate arithmetic means. Figures at the bottom show the corresponding maximum values for strain ATCCI 3124.

cultured under the conditions found to be optimal for strain ATCCI3I24 (type A). These strains gave higher bacterial dry weight yields than the ATCC type A strain, but the production of phospholipase, haemolysin, lethal toxin and the number of precipitating extracellular antigens was equal or lower (Fig. 2). No significant difference was apparent between the strains isolated from clinical infections and those from faecal samples from healthy persons.

\section{Typing with standard antisera}

The culture supernatants from fermenter cultures of each of the four ATCC type strains were mixed with commercial antisera types $A$ to $D$ according to the standard scheme (Hauschild, 1971; Smith, I973). Of the I6 neutralization tests performed, five gave erratic results. In two tests this was due to high toxic activity in the supernatant and was corrected for by diluting the supernatant prior to the neutralization test. However, neutralization of the toxic activity of type $\mathrm{D}$ supernatant with type $\mathrm{A}$ or $\mathrm{C}$ antiserum was complete, indicating that this strain did not produce epsilon-toxin. Furthermore, no activation of a protoxin by trypsin treatment was observed. We cannot explain the fifth faulty neutralization test. These results illustrate how sensitive the commonly used in vivo test for typing $C$. perfringens is to the culture conditions.

\section{Epsilon-toxin}

Attempts to activate epsilon-toxin from a protoxin in the culture fluids of types B and D strains by treatment with trypsin were not successful. None of the ATCC or NCTC strains gave culture supernatants in which a higher toxicity was detected in the mouse after treatment with trypsin. However, when cultivated in chopped-meat broth in static culture, supernatants of strains ATCC3626 (type B) and NCTC8346 (type D) possessed lethal activity which increased from 4 to $\mathrm{I} 28 \mathrm{LD}_{50} \mathrm{ml}^{-1}$ upon trypsin treatment. Production of epsilonprotoxin was also demonstrated with some other strains of types B and D (kindly supplied by Dr L. D. S. Smith) in fermenter cultures. 


\section{DISCUSSION}

Sargeant (1968) pointed out the advantages of culturing anaerobes in stirred fermenters under controlled conditions. Optimal conditions (medium, $\mathrm{pH}$, temperature, strain etc.) for production of phospholipase $\mathrm{C}$ and theta-haemolysin by type $\mathrm{A}$ strains were investigated earlier (Nord et al., 1974). Similar conditions were used in this study to compare strains of types $\mathrm{A}$ to $\mathrm{D}$ with respect to optimum $\mathrm{pH}$ for growth and formation of extracellular toxins. The importance of $\mathrm{pH}$ control for production of clostridial toxins was pointed out by Pjvnick et al. (1964) and Hauschild (1966, I97I): Hauschild showed a selective stimulation of toxinogenesis, or possibly toxin release, at the optimum $\mathrm{pH}$ for growth of type $\mathrm{C}$ and D strains. In our studies, toxin production was associated with active growth (Fig. I), as was reported by Gale \& van Heyningen (1942) and Raynaud et al. (1955).

The absence of production of detectable epsilon-protoxin by types B and D strains in fermenter cultures, as evidenced by the failure of trypsin activation, is remarkable. In contrast, upon growth in static culture in chopped-meat medium, two of the type culture strains produced detectable epsilon-toxin. In ATCC3626 type B strain, the total lethal activity per $\mathrm{ml}$ of supernatant was of the same order as in fermenter cultures. The lack of a trypsin-activated lethal toxin in fermenter cultures may be explained either by a need for chopped-meat constituents for production of epsilon-protoxin or by a spontaneous activation of the protoxin under the culture conditions used. Weak proteolytic activity was found in all fermenter supernatants.

Our results for growth and toxin production in fermenter cultures were very similar to the findings of Pivnick et al. (1964) for batch cultures with $\mathrm{pH}$ control, but in no case were their observed high yields of epsilon-toxin obtained $\left(10^{3}\right.$ to $10^{5}$ minimum lethal doses per $\mathrm{ml}$ ). The use of different bacterial strains for cultures and different strains of mice for toxicity testing may partly explain these discrepancies.

Strains of $C$. perfringens types A to D from NCTC were cultured under the same conditions as the corresponding ATCC strains. The NCTC strains had different growth characteristics including different $\mathrm{pH}$ optima. For simplicity, they were all cultured at pH 6.4 and, under these conditions, none of them produced more phospholipase, haemolysin or lethal toxins than the corresponding ATCC strain. These data indicate that the growth characteristics of $C$. perfringens strains do not depend on their respective type designation, but on strain-associated properties.

Twenty-eight newly isolated strains of $C$. perfringens type A were also investigated for growth and production of extracellular toxins, but under the conditions used they were not superior to strain ATCCI3I 24 (Fig. 2). Forget et al. (1969), in a study of different characters of $C$. perfringens type A, claimed that the toxicity of culture supernatant fluids for mice correlated with virulence. However, we found no difference in growth or toxin formation between strains from clinical cases of gas gangrene and those from faecal specimens from healthy persons. There was also no correlation between the toxicity of supernatants and the formation of phospholipase $\mathrm{C}$ or haemolysin in these strains. Thus, neither of these two toxins seems to be solely responsible for the lethal activity of type A culture supernatants.

Rapid identification of $C$. perfringens from clinical specimens can be achieved by growing the organism at $45{ }^{\circ} \mathrm{C}$ for a few hours in a proteose peptone medium containing glucose, and detecting characteristic metabolites by gas-liquid chromatography (Holdeman \& Moore, 1973). There is, however, a need for standardized and less laborious in vitro assays for serological subtyping. Reproducible methods of production of extracellular toxins and 
enzymes are a prerequisite for the standardization of preparations of antigen and antisera for such tests. This investigation demonstrates that the strain selected and the culture conditions used strongly influence the final yield of extracellular products.

The skilful technical assistance of Christina Hedberg is greatly appreciated. This investigation was supported by grant no. $506 \mathrm{H}_{557}$ from the Swedish National Defence Research Institute. One of us (R. M.) has a research position at the Swedish Medical Research Council $(40 \mathrm{P}-4576)$.

\section{REFERENCES}

Arvidson, S., Holme, T. \& WAdSTröm, T. (I97I). Influence of cultivation conditions on the production of extracellular proteins by Staphylococcus aureus. Acta pathologica et microbiologica scandinavica 79B, 399-405.

Forget, A., Paquette, G., Roy, A. \& Fredette, V. (I969). Correlations between virulence and other characters of Clostridium perfringens type A. Applied Microbiology 18, 668-676.

Gale, E. F. \& VAN Heyningen, W. E. (1942). The effect of the $\mathrm{pH}$ and presence of glucose during growth on the production of $\alpha$ and $\theta$ toxins and hyaluronidase by Clostridium welchii. Biochemical Journal $3^{6}$, 624-630.

Goldbarg, J. A. \& Rutenberg, A. M. (1965). The colorimetric determination of leucine aminopeptidase in urine and serum of normal subjects and patients with cancer and other diseases. Cancer II, 283-287.

HausChild, A. H. W. (1966). Selective effect of $\mathrm{pH}$ on the production of extracellular protein by Clostridium perfringens type D. Journal of Bacteriology 92, 800-80I.

HAUSCHILD, A. H. W. (I97I). Clostridium perfringens toxins types B, C, D and E. In Microbial ToxinsBacterial Protein Toxins, vol. I I A, pp. I 59-188. Edited by S. Kadis, T. C. Montie and S. J. Ajl. New York and London: Academic Press.

Holdeman, L. V. \& Moore, W. E. C. (1973). Anaerobe Laboratory Manual. Blacksburg, Virginia, U.S.A.: Virginia Polytechnic Institute and State University.

LYNCH, K. L. \& MoskowitZ, M. (1968). Relationship of route of inoculation and nature of toxin preparation to bioassay of Clostridium perfringens alpha-toxin in mice. Journal of Bacteriology 96, 1920-1924.

Möllby, R. \& WAdSTRöm, T. (1973). Purification of phospholipase C (alpha-toxin) from Clostridium perfringens. Biochimica et biophysica acta 321, 569-584.

Murphey, W. H., Barnaby, C., Lin, F. J. \& Kaplan, N. O. (1967). Malate dehydrogenases. II. Purification and properties of Bacillus subtilis, Bacillus stearothermophilus and Escherichia coli malate dehydrogenases. Journal of Biological Chemistry 242, I548-1 559.

Nord, C.-E., Möllby, R., Smyth, C. J. \& Wadström, T. (1974). Formation of phospholipase C and thetahaemolysin in pre-reduced media in bath and continuous culture of Clostridium perfringens type A. Journal of General Microbiology 84, I I 7-1 27.

Pivnick, H., Habeeb, A. F. S. A., Gorenstein, B. S., Stuart, P. F. \& Hauschild, A. H. W. (I964). Effect of $\mathrm{pH}$ on toxinogenesis by Clostridium perfringens type C. Canadian Journal of Microbiology ro, 329344 .

Raynaud, M., Turpin, A., Mangalo, R. \& Bizzini, B. (1955). Croissance et toxinogenèse. Annales de l'Institut Pasteur 88, 24-44.

SARGEANT, K. (I968). Improvement of yields in anaerobic cultures. Chemistry and Industry, no. 85-88.

SмITH, L. D. S. (1973). The Clostridia. In Handbook of Microbiology: I, Organismic Microbiology, pp. 8996. Edited by A. I. Laskin and H. A. Lechevalier. Cleveland, Ohio, U.S.A.: Chemical Rubber Co. Press.

Smith, L. D. S. \& Holdeman, L. V. (1968). The Pathogenic Anaerobic Clostridia. Springfield, Illinois, U.S.A.: Charles C. Thomas.

WEEKE, B. (1973). Crossed immunoelectrophoresis. Scandinavian Journal of Immunology (Suppl. I/73) 2. 47-69.

WILlIS, A. T. (1969). Clostridia of Wound Infection. London: Butterworths.

WILSDON, A. J. (I93I). Reports of the Institute for Pathology, University of Cambridge, 2nd report, pp. 53-85. 